\title{
Habitat preferences of the sea urchin Paracentrotus lividus
}

\author{
Stefania Pinna ${ }^{1, *}$, Antonio Pais ${ }^{2}$, Paolo Campus $^{2}$, Nicola Sechi ${ }^{1}$, Giulia Ceccherelli ${ }^{1}$ \\ ${ }^{1}$ Dipartimento di Scienze Botaniche, Ecologiche e Geologiche, Università di Sassari, 07100 Sassari, Italy \\ ${ }^{2}$ Sezione di Acquacoltura e Gestione delle Risorse Acquatiche, Dipartimento di Scienze Zootecniche, Università di Sassari, \\ 07100 Sassari, Italy
}

\begin{abstract}
Population structure of the sea urchin Paracentrotus lividus seems to vary depending on the habitat, as, on average, urchin density is higher on rocks, and size is larger in Posidonia oceanica seagrass. Here, we tested the hypothesis that $P$. lividus would choose $P$. oceanica rather than rocky habitat due to the greater availability of shelter and food in the seagrass. We conducted 2 experiments by using aquaria divided into 2 equal sections, each containing an array of 2 habitats: natural P. oceanica (P) and rocks (R) in the first experiment and natural (NP) and artificial (AP) P. oceanica in the second (to highlight the reason for preference). Each experiment included 2 experimental stages of no-choice (Stage 1) and choice (Stage 2): in the 2 no-choice treatments, sections were filled with the same habitat, and in the 2 choice treatments, sections were filled with $\mathrm{P}$ and R in Expt 1 and NP and AP in Expt 2. Under the null hypothesis that preference of habitat is random, the expected numbers of sea urchins that were distributed in the 2 sections of the habitat after $24 \mathrm{~h}$ were estimated by using formulae derived from maximal likelihood estimates. The results evidenced a preference by $P$. lividus for $P$. oceanica habitat rather than rocky habitat in the first experiment and for natural $P$. oceanica rather than artificial seagrass in the second experiment, thus suggesting that $P$. lividus individuals searched for a well-structured habitat where they could find both shelter and food.
\end{abstract}

KEY WORDS: Habitat preference 'Paracentrotus lividus Posidonia oceanica ' Habitat use · Spatial distribution $\cdot$ Artificial seagrass canopy $\cdot$ Sea urchins

Resale or republication not permitted without written consent of the publisher

\section{INTRODUCTION}

Different distribution patterns of marine organisms among habitats can be explained, after widespread recruitment, by adult choice of favoured habitat actively selected from a variety of potential accessible habitats (Crowe \& Underwood 1998). In addition, the patterns of distribution and abundance of animals are frequently explained by the behaviour of the species considered, or of those species that they interact with (Chapman 2000). Further, since habitat selection depends on the availability of different quality habitats, the distribution and abundance of organisms are often not independent of the neigh- bouring habitats (Russell et al. 2005). In fact, movement among habitat patches is not simply a function of an organism itself, but also depends on the landscape through which it should move. Moreover, the dispersal process depends on the interaction between species attributes and landscape structure, or connectivity, originally defined as 'the degree to which the landscape facilitates or impedes movement among resource patches' (Taylor et al. 1993). Connectivity is a major determinant of the immigration rate of organisms to habitat patches, and this accentuates the dependence of movement on landscape structure, which suggests that connectivity is species- and landscape-specific (Tischendorf \& 
Fahrig 2000, Kadoya 2009). Thus, spatial arrangement of habitat (i.e. size and patchiness) influences habitat utilisation and causes the spatial distribution of organisms (With et al. 1997).

Seagrass meadows usually host a greater number of invertebrates and fish species than unvegetated substrates (Smith et al. 2008). Further, seagrass beds form naturally patchy habitats with large areas of seagrass-sand or seagrass-rock edges. Thus, since seagrass patches embedded with rocky habitats can affect the movement of animals that use both these habitats as living sites, the knowledge of the movement patterns of such organisms within the 2 habitats is crucial in understanding and predicting their population dynamics in space and time. Connectivity among habitats may influence the patterns of species distribution across ecosystems, as the habitat choice for some species can only be possible if habitats are contiguous: for example, connectivity between rocky habitats and seagrasses can be reduced or prevented by the presence of sandy areas between them (Fagan et al. 1999, Fernandez et al. 2001, Ceccherelli et al. 2009a, Prado et al. 2009).

Numerous studies have investigated patterns of spatial distribution among habitats by both marine and terrestrial organisms (see review by Underwood et al. 2004). Often, the 'preference' is used to explain the observed patterns of distribution. Specifically, the existence of a preference requires (and implies) an outcome of behaviour of an organism (Singer 2000). Thus, preference for or choice of habitats means that animals have actively selected 1 (or more) habitat(s) from a variety of potential habitats encountered (Rosenzweig 1981, Manly et al. 1993). Experimental demonstration of preference requires no-choice and choice tests (Underwood \& Clarke 2005). In laboratory experiments, some form of 'choice chamber' has usually been used wherein the same type (no-choice test) or different types (choice test) of habitats are offered to individuals who are released to move freely (Crowe \& Underwood 1998 and references therein).

In the Mediterranean, the sea urchin Paracentrotus lividus (Lamarck) is common in shallow subtidal rocky habitats and in Posidonia oceanica (L.) Delile seagrass beds where it often dwells on rhizomes among shoots. In rocky habitats, it grazes in complex algal assemblages (e.g. Benedetti-Cecchi et al. 1998, Hereu 2006), whereas in P. oceanica beds, it feeds on epiphytes (Nédelec \& Verlaque 1984, Shepherd 1987, Tomas et al. 2005, 2006) and along the whole leaf (Pinna et al. 2009). P. lividus population structure seems to differ between these 2 habitats: mean den- sity of individuals is higher on rocks than in P. oceanica meadows (Tomas et al. 2004, Boudouresque \& Verlaque 2007, Ceccherelli et al. 2009a), whereas mean size is larger in this latter habitat, where about $70 \%$ of individuals are $>60 \mathrm{~mm}$ in test diameter (Tomas et al. 2004, Ceccherelli et al. 2009a). However, determinants for such a pattern of distribution still need to be fully understood. For example, higher $P$. lividus recruitment to rocky habitats than seagrass has been estimated, as settlement in $P$. oceanica meadows is often unsuccessful due to the physical structure of the seagrass (Tomas et al. 2004, Prado et al. 2009). Therefore, the adult populations in $P$. oceanica meadows could be the result of migration from the contiguous rocky habitats (Tomas et al. 2004, Ceccherelli et al. 2009a). In addition, although extensive literature is devoted to understanding the importance of many of these features in the P. lividus population of rocky habitats (Crook et al. 2000, Fernandez et al. 2001, Guidetti 2004, Tomas et al. 2004, Hereu et al. 2005), migration from one habitat to another is still poorly understood.

Sea urchins' movements can be triggered and influenced by a range of factors. For example, Kitching \& Ebling (1961) suggested that migrations are dependent on urchin density and food availability; a lack of food causes the need for long foraging trips (Palacín et al. 1997). Further, Barnes \& Crook (2001) showed that sea urchin size, covering behaviour (i.e. placing items from the surrounding environment onto their dorsal surface), and season can be important determinants of migratory behaviour. However, the presence of predatory fish influences sea urchin behaviour by causing the urchins to shelter themselves, thus diminishing their diel foraging activity (Carpenter 1984, Scheibling \& Hamm 1991, Sala 1996). Thus, Paracentrotus lividus shows a circadian pattern of activity, with more active individuals during the night (Dance 1987, Hereu 2005), probably as a defence against diurnal predators. Recently, short-distance movements toward seagrass patches have been estimated for both small and large P. lividus individuals (Ceccherelli et al. 2009b), although whether they occurred intentionally or randomly is not known.

Overall, until experiments are conducted on habitat preference by Paracentrotus lividus and on the mechanisms involved, any movement toward the seagrass from the rock cannot be seen as a choice determined. In the Posidonia oceanica habitat, P. lividus could benefit from effective shelter, given the high habitat complexity and food availability (e.g. Cebrián et al. 1996, Prado et al. 2007, Farina et al. 2009). 
We conducted 2 laboratory experiments to study habitat preference by Paracentrotus lividus. Testing for a behavioural preference requires that individuals exercise non-random behaviour in choosing the habitat when presented with an array of 2 or more types of habitats; thus, a null hypothesis is required against which to test for departures from random expectation. Experimental demonstration of preference thus requires 2 experimental stages that provide no-choice and multiple-choice tests (Liszka \& Underwood 1990, Underwood \& Clarke 2005).

To explain habitat preference, we considered only Paracentrotus lividus individuals who were distributed in an area where patches of Posidonia oceanica were next to rocky habitat. In each experiment, the sea urchins were provided with an array of 2 habitats: natural P. oceanica (P) and rocks (R) in the first experiment (Expt 1) and natural P. oceanica (NP) and artificial $P$. oceanica (AP) in the second experiment (Expt 2). Each experiment included 2 experimental stages of no-choice (Stage 1) and choice (Stage 2).

Specifically, we hypothesised that if there were a preference for Posidonia oceanica, then the number of Paracentrotus lividus individuals remaining after $24 \mathrm{~h}$ would be greater in sections occupied by natural $P$. oceanica. Thus, $P$. lividus would choose (1) $P$. oceanica rather than a rocky habitat for the higher shelter and food availability and (2) natural P. oceanica due to the lack of food availability in the artificial P. oceanica. In Expt 2, the artificial seagrass, which reproduces the natural canopy structure, should offer the same chance of sheltering to sea urchins and, thus, to us, the opportunity to discern the role of food attraction in their movements.

\section{MATERIALS AND METHODS}

For the set up of both experiments, adults of Paracentrotus lividus, Posidonia oceanica shoots and boulders covered by macroalgal assemblages were collected from the field and taken to the laboratory to reproduce $P$. oceanica and rocky habitats, respectively. The collection of all samples was done in a small bay in the Gulf of Alghero (north western Sardinia, Italy), where at $\sim 5 \mathrm{~m}$ of depth, patches of the 2 habitats are naturally arranged, and individuals of $P$. lividus occur in both. In the field, the average $P$. oceanica shoot density was quantified (490 \pm 3.52 shoot $\mathrm{m}^{-2}$, mean $\pm \mathrm{SE}, \mathrm{n}=10$ ) in order to reproduce in the laboratory the natural shoot density of the seagrass. The epiphytes present on the leaves were not removed. Their cover was very low, and they were mostly composed by encrusting Corallinales and Bryozoa, and neither Dictyotales nor algal turfs were found. To reproduce the rocky habitat, boulders with an external face of about $25 \times 15 \mathrm{~cm}$ were collected and arranged in aquaria so that the sizes of cavity openings between boulders ranged from $5 \times 3 \mathrm{~cm}$ to $7 \times 5 \mathrm{~cm}$, which was similar to the natural array where they had been collected. Further, only boulders totally covered by macroalgae were chosen. Macroalgal assemblages were composed of several palatable species, such as Padina pavonica, Laurencia spp., Dictyotales, Sphacelariales and algal turfs (Verlaque 1987, Benedetti-Cecchi et al. 1998, Bulleri et al. 1999). The artificial $P$. oceanica was made by using plastic seagrass units, mimicking natural seagrass, so that shelter but no food could be provided. Artificial leaves were made of green plastic strips and arranged to form shoots with the density and length of leaves resembling natural $P$. oceanica at the site where natural seagrass shoots were collected.

Two experiments were conducted by using closed re-circulating aquaria of $1 \times 1 \times 0.5 \mathrm{~m}$ in size (ca. $500 \mathrm{l}$ of seawater) divided into 2 equal sections, each containing an array of 2 habitats: natural Posidonia oceanica (P) and rocks (R) in Expt 1 and natural (NP) and artificial (AP) P. oceanica in Expt 2. All aquaria had a constant supply of oxygen throughout the whole experiment, and they were kept at 17 to $18^{\circ} \mathrm{C}$ on a 12:12 h light-dark cycle. In addition, salinity (35 psu), pH (7.9) and oxygen (8.6 mg l-1) were kept constant. For each experiment, 4 treatments (with 3 replicates each) were used: 2 no-choice (treatment 1 and treatment 2, hereafter T1 and T2) and 2 choice treatments (T3 and T4). In the no-choice treatments of both experiments, the 2 sections were occupied by the same habitat $(\mathrm{P} / \mathrm{P}, \mathrm{R} / \mathrm{R}$, and NP/NP, AP/AP, for Expts 1 and 2, respectively), whereas in the choice treatments, the 2 sections were occupied by the 2 different habitats (P/R and NP/AP for Expts 1 and 2, respectively; Fig. 1). We exposed Paracentrotus lividus individuals to habitats in 2 stages for each experiment: Stage 1, in which we estimated the number of sea urchins that were distributed in the 2 sections of habitats when only 1 type of habitat was offered (nochoice treatments: T1 and T2) and Stage 2, in which we estimated the number of $P$. lividus that were distributed in the 2 sections of habitats when 2 different habitats were offered (choice treatments: T3 and T4).

For both experiments, the natural and the artificial shoots were attached to a $50 \times 100 \mathrm{~cm}$ frame of plastic-coated iron with a $2 \times 2 \mathrm{~cm}$ mesh. For the AP habitat, each shoot was made of 3 folded $60 \mathrm{~cm}$ strips (corresponding to 6 leaves of $30 \mathrm{~cm}$ ), and in total, 
Expt 1

Stage 1: no choice

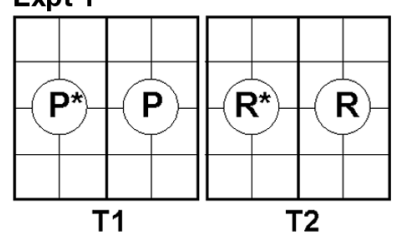

Expt 2

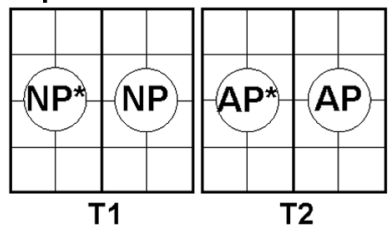

Stage 2: choice
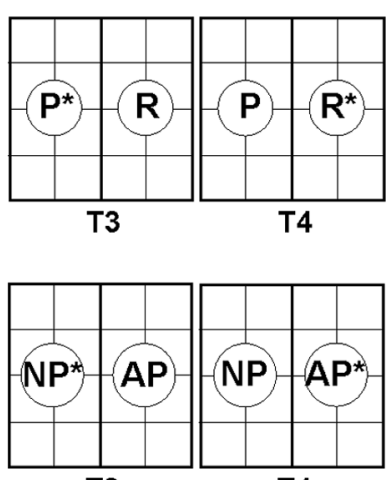

T3
T4
Fig. 1. Description of treatments (T1 to T4) used in the 2 experiments. In Expt 1, P: Posidonia oceanica, R: rocky habitat. In Expt 2, NP: natural Posidonia oceanica, AP: artificial $P$. oceanica. ${ }^{*}$ indicates the section where the sea urchins were placed at the start of the experiment

245 shoots were tied to fill a whole section. The same frame used to tie Posidonia oceanica shoots was positioned on the aquarium floor even under the boulders, to minimise the effect of possible artefacts. Further, to ensure that the artificial leaves reduced irradiance similarly to natural $P$. oceanica leaves, light measurements were taken in the aquarium beneath the 2 types of seagrass canopy by using a quantum photometer $(\mathrm{NP}=29.5 \pm 2.05 \mathrm{~lx}$ and $\mathrm{AP}=$ $28.0 \pm 2.60 \mathrm{~lx}$, mean $\pm \mathrm{SE}, \mathrm{n}=6$ ) .

The aquarium floor size was judged crossable by Paracentrotus lividus individuals in $24 \mathrm{~h}$ (experiment duration), as the mean linear distance travelled in this time reaches up to $130 \mathrm{~cm}$ (estimate taken in areas with high predator density by Hereu 2005). Large $P$. lividus individuals $(49.8 \pm 0.2 \mathrm{~mm}$ in test diameter, mean $\pm \mathrm{SE}, \mathrm{n}=240$ ) were used, because a higher number of adult individuals are distributed in Posidonia oceanica meadows that are contiguous to rocky habitats (Ceccherelli et al. 2009a). Sea urchins were collected and kept starved for $48 \mathrm{~h}$ before starting the experiments. At the start of both experiments, $10 P$. lividus individuals were positioned in the middle of 1 section of each aquarium (Fig. 1). In total, 120 individuals were used for each experiment, for independent measurements (Underwood et al. 2004). After the placement, the position of the individuals was recorded after 3,6 , and $24 \mathrm{~h}(\mathrm{~h} 3, \mathrm{~h} 6$ and $\mathrm{h} 24$, respectively). To localise the individual position in the whole aquarium, a plastic quadrate divided into 16 subquadrates of $25 \times 25 \mathrm{~cm}$ was used. At the end of each experiment, the gut content of all individuals was observed by dissecting the sea urchins and examining the material under a microscope at $40 \times$.

\section{Statistical analyses}

Under the null hypothesis that habitat preference is random, the expected numbers of sea urchins that were distributed in the 2 sections of habitat after $24 \mathrm{~h}$ were estimated by using formulae described by Underwood \& Clarke (2005) derived from maximal likelihood estimates. For both experiments, data from Stages 1 and 2 were used in analyses by using these formulae. Thus, the null hypothesis of no preference was that the ratio of the proportion of Paracentrotus lividus individuals, who stayed in a section of habitat when choice was possible, was equal to that calculated when only 1 type of habitat was presented:

$$
H_{0}: q_{1} / q_{2}=p_{1} / p_{2}\left(\text { or } H_{0}: q_{1}=\theta p_{1} ; q_{2}=\theta p_{2}\right)
$$

where $p_{1}$ and $p_{2}$ are the proportions of $P$. lividus individuals who stayed in the initial section of a habitat when it was presented in a no-choice treatment (estimates provided from Stage 1); $q_{1}$ and $q_{2}$ are the proportions of $P$. lividus individuals who stayed in the initial section of a habitat when there was a choice (estimates provided from Stage 2); and $\theta$ is a constant, unknown parameter. The numbers of sea urchin individuals recorded in the initial section after $24 \mathrm{~h}$ were then compared with the numbers expected on the basis of no preference (i.e. the null hypothesis) by using $\chi^{2}$ tests with $k-1$ degrees of freedom, where $k$ is the number of habitats available.

\section{RESULTS}

As predicted, a clear trend in preference for Posidonia oceanica by Paracentrotus lividus was evidenced (Table 1, Fig. 2). In each experiment, there were significant differences in the number of individuals found among treatments. In Stage 1, in the nochoice treatments (T1 and T2) of both experiments, a relatively large number of $P$. lividus individuals was found in the section in which they had been initially placed $\left(63.3 \%\right.$ in $\mathrm{P}^{*} / \mathrm{P}$ and $\mathrm{NP}^{*} / \mathrm{NP}, 70.0 \%$ and $76.7 \%$ in $\mathrm{R}^{*} / \mathrm{R}$ and $\mathrm{AP}^{*} / \mathrm{AP}$, respectively, where the asterisks indicate the sections in which the sea urchins were placed at the start of the experiment). In Stage 2, when presented with a choice of habitats (choice treatments: T3 and T4 in both experiments), a large number of $P$. lividus individuals tended to stay in the section in which they had been initially placed when it was occupied by P. oceanica (78.3 and $66.7 \%$ in $\mathrm{P}^{*} / \mathrm{R}$ and $\mathrm{NP}^{*} / \mathrm{AP}$, respectively). In contrast, sea urchins tended to move to the other section when they had been initially placed in rocks and artificial 
P. oceanica (21.7 and $33.3 \%$ in $\mathrm{P} / \mathrm{R}^{*}$ and NP/AP*, respectively; Table 1, Fig. 2).

The $\chi^{2}$ tests demonstrated that a significantly greater number of sea urchins was recovered of those initially placed in the sections occupied by Posidonia oceanica than in those occupied by rocky habitat or artificial P. oceanica (Table 1). Thus, the analyses reject the null hypothesis of both experi-

Table 1. Paracentrotus lividus. Test of preference done from paired data of Stage 1 (no choice) and Stage 2 (choice) for the observed numbers of $P$. lividus individuals and the expected values in both experiment. Degrees of freedom of $\chi^{2}$ test are $k^{-1}$, where $k$ is the number of choices of habitat. $\chi^{2}$ tests indicate whether the proportions of habitat preferred when choice was present significantly differed to when choice was absent. See legend of Fig. 1 for explanations.

Significant differences $(p<0.05)$ are indicated in bold

\begin{tabular}{|c|c|c|c|c|c|}
\hline & \multicolumn{2}{|c|}{- Expt $1-$} & & \multicolumn{2}{|c|}{- Expt 2} \\
\hline & Stage 1 & tage 2 & & Stage 1 & Stage 2 \\
\hline \multicolumn{6}{|c|}{ Observed } \\
\hline $\mathrm{P}$ & 19 & 25 & NP & 19 & 24 \\
\hline $\mathrm{R}$ & 21 & 8 & $\mathrm{AP}$ & 23 & 14 \\
\hline \multicolumn{6}{|c|}{ Expected } \\
\hline $\mathrm{P}$ & 19.8 & 16 & NP & 20.3 & 18 \\
\hline $\mathrm{R}$ & 20.1 & 17 & $\mathrm{AP}$ & 21.9 & 20 \\
\hline$\chi^{2}$ & \multicolumn{2}{|c|}{9.9} & & \multicolumn{2}{|c|}{3.94} \\
\hline $\mathrm{p}$ & \multicolumn{2}{|c|}{0.0016} & & \multicolumn{2}{|c|}{0.0471} \\
\hline
\end{tabular}

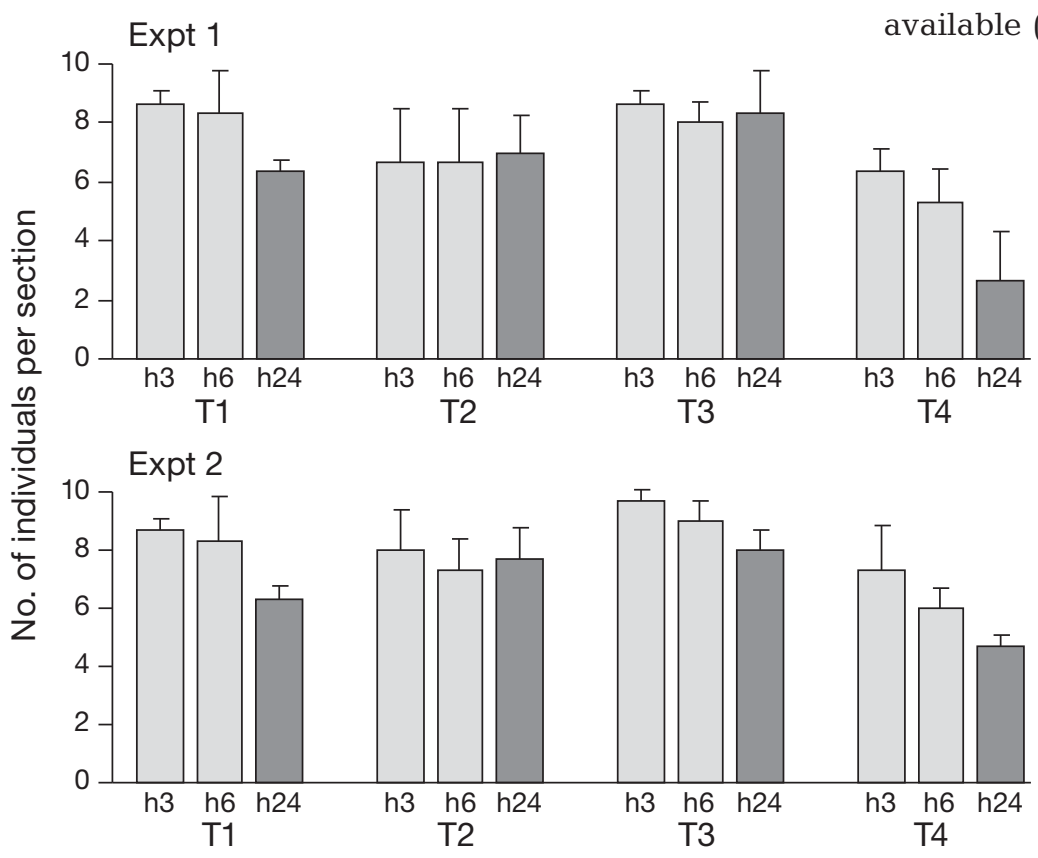

Fig. 2. Paracentrotus lividus. Number of individuals in Expt 1 and Expt 2 after 3,6 , and $24 \mathrm{~h}(\mathrm{~h} 3, \mathrm{~h} 6$, and h24) in the section where they were initially placed (mean + SE). T1, T2, T3 and T4 refer to treatments. Dark grey bars refer to data used for analyses ments and demonstrate that Paracentrotus lividus exercises non-random behaviour when a choice is present. Further, sea urchins' movements were different in choice treatments than in no-choice treatments. In fact, in choice treatments, a lesser change of position was recorded when sea urchins were positioned in P. oceanica; whereas when they started from rocky sections or artificial seagrass, they soon moved toward P. oceanica, as evidenced by the decrease in the number of individuals over time (Fig. 2).

In addition, the material found at the end of the experiments in the gut content of the individuals used revealed that a large number fed on Posidonia oceanica, as indicated by the high percentage of guts containing fresh leaves: $53.3 \%$ (T1), $0 \%$ (T2), $66.6 \%$ (T3) and $74.2 \%$ (T4) in Expt 1 and $53.3 \%$ (T1), $0 \%$ (T2), $46.6 \%$ (T3) and $33.3 \%$ (T4) in Expt 2. The percentage of macroalgae in the gut contents was $33.3 \%$ (T1), $76.7 \%$ (T2), $26.7 \%$ (T3) and $32.6 \%$ (T4) in Expt 1 and $33.3 \%$ (T1) and $0 \%$ (in T2, T3 and T4) in Expt 2.

\section{DISCUSSION}

Our results clearly supported the initial hypotheses that Paracentrotus lividus moves more often into Posidonia oceanica habitat than into rocky or artificial seagrass habitat. A great number of sea urchins moved toward the seagrass where a choice was available (T4 in Expt 1). The outcome was the result of different sea urchins' movements and occupation of habitats. In fact, P. lividus individuals, when positioned in P. oceanica (T1 and T3), tended not to move immediately, whereas when positioned in rocky sections (T4), they moved away soon and, in rocky habitat, they settled in the cavities among boulders rather than on the surfaces, thus exhibiting cryptic behaviour. Overall, this demonstrates a preference for $P$. oceanica.

Many studies have suggested possible non-random patterns of association between Paracentrotus lividus and the habitats available based on spatial distribution data (Fernandez et al. 2001, Tomas et al. 2004, Prado et al. 2009), and this study is the first attempt to experimentally demonstrate a preference for Posidonia oceanica by the sea urchin. Our results are in accordance with Ceccherelli et al. (2009b), who found a large number of $P$. lividus individuals migrat- 
ing toward $P$. oceanica patches in the field, although in that study it was not known whether this occurred as a result of intentional searching for that habitat. Data now available indicate that in the laboratory, when $P$. lividus individuals were outside a refuge, as they were at the start of our experiments, they searched for a well-structured habitat where they could find both shelter and food. Specifically, even if we did not mark individuals to avoid additional disturbance, the manipulation of the individuals could have alarmed them and, thus, have affected their movements, thereby causing the search for a refuge (but see Bulleri et al. 2009).

The mechanisms that could have driven the choice of Paracentrotus lividus for Posidonia oceanica over rocky habitat were defined in Expt 2. In fact, in Expt 1, where the habitats used were both natural and provided different palatable material and different options for shelter, P. lividus could have been attracted either by the structure of the seagrass or by the leaf material. In fact, the gut content of the sea urchins has evidenced that feeding on $P$. oceanica did occur in treatments where it was available (T1, T3 and T4 in Expt 1), and some individuals were observed while feeding on the leaves. Leaf material in the gut content was easily recognisable, whereas epiphytes were not detectable. Several authors have already reported that the trophic interactions between $P$. oceanica and $P$. lividus are mediated by epiphytes that appear to make the leaves more edible for the herbivore (Alcoverro et al. 1997, Tomas et al. 2005, 2006, Prado et al. 2007). However, in our study, we do not believe that epiphyte occurrence could have driven sea urchin choice because of their low cover and palatability of taxa. Conversely, a very low quantity of fleshy algae was recorded in the gut content, although the macroalgae on boulders are reported to be palatable for this sea urchin (Frantzis et al. 1988, Bulleri et al. 1999), despite the narrow literature about their secondary metabolites (Boudouresque \& Verlaque 2007).

Hence, in Expt 1, the mechanism regulating preference cannot be discerned, as the effect due to chemosensory perception is confounded by the effect of spatial vision on preference. The results of Expt 2 disentangled these mechanisms, suggesting that Paracentrotus lividus was attracted to Posidonia oceanica by chemotaxis. In fact, since the NP and AP habitats had the same structure, and the shade under the 2 canopy types was very similar, spatial vision should not have driven the movements of the sea urchins. The only mechanism responsible for their change in position could therefore be the perception of the nat- ural habitat (palatable material to feed on). In fact, although the extent of their perception of the habitat landscape is still unknown, sea urchins' chemosensory competence is considered a behavioural response to food (Hagen \& Mann 1994, Rodriguez \& Ojeda 1998, Hagen et al. 2002). In addition, the sea urchins' spatial vision of the environment, which is possible due to the photosensitivity and perception of roughness of the substrate, can induce a willingness to reach shelter (Blevins \& Johnsen 2004, Yerramilli \& Johnsen 2010). Thus, these results evidenced intentional searching for a particular habitat that can provide both shelter and food, thus refining the general belief, previously based simply on gut content, that $P$. lividus is able to adapt widely to the availability of food resources (Zupo \& Fresi 1984). However, field experiments using natural and artificial habitats are needed to develop a mechanistic understanding of how the presence of the seagrass $P$. oceanica canopy next to rocky habitats affects the distribution of $P$. lividus.

Patterns of association can be non-random because of features of the animal-habitat or consumer-diet interaction, by properties of the habitat (or diet) or by behavioural properties of the consumer (and presumably by combinations of these) without preferences being exercised (Underwood et al. 2004). All of these components should be considered when preferences have been demonstrated and experimental analyses of the processes causing preference are attempted. Accordingly, the highlighted preference of Paracentrotus lividus for Posidonia oceanica over rocky habitats may be the result of positive properties of the seagrass (e.g. it contains food and refuges) or negative properties of other habitats (e.g. exposure to predators, hydrodynamics and availability of less palatable food) or some combination of both. Further, we firmly believe that when a meadow is next to a rocky substrate (as in this case), then the movement of $P$. lividus across habitats is possible, rather than if there were sand. In fact, the presence of sediments has been reported to affect the distribution of $P$. lividus (Ceccherelli et al. 2009a, Farina et al. 2009, Prado et al. 2009) and prevent grazing (Bulleri et al. 2011). Based on these issues, we expect that the movement of sea urchins will be a function of the occurrence of sandy bottoms among patches of rocky and $P$. oceanica habitats. It follows that habitat spatial arrangement and the quality of habitats should be considered when analysing $P$. lividus distribution patterns, because they affect the degree of connectivity, or isolation between habitats. Indeed, the choice of moving toward the seagrass by $P$. lividus is likely 
to depend on the structure of the canopy (i.e. shoot density and leaf length), the presence of mattes (i.e. where rhizomes are unburied; Farina et al. 2009, Prado et al. 2009) and the habitat neighbourhood; we suggest that it could help to explain variability in the spatial distribution of $P$. lividus between habitats across sites.

Distribution and habitat requirements of a species are important elements for its conservation and, therefore, understanding the nature of a preference extends the comprehension of the interaction between the species and the distribution of the habitats. Overall, conservation of species is often based on conservation of their habitats or microhabitats (Margules et al. 1994, Olabarria et al. 2002, Underwood et al. 2004) and, thus, understanding the mechanism and movement pattern at small spatial scales can improve the knowledge of the individuals' ability to take advantage of different types of habitat. Investigations should therefore be done not at scales relevant to human perception, but at a scale appropriate to the movement of organisms across the landscape (e.g. Wiens \& Milne 1989, Collinge \& Forman 1998). Knowledge of whether observed non-random patterns of association are caused by preference is of a great value to ecologists for predicting and understanding responses to changes in the availability of resources (Jackson \& Underwood 2007). In addition, a mechanistic understanding of the associations between species and particular types of habitats is essential to improve predictions of species' responses to loss of natural habitats.

Acknowledgements. We thank P. Uccello, A. Mazza and G. Meloni for technical support.

\section{LITERATURE CITED}

Alcoverro T, Duarte CM, Romero J (1997) The influence of herbivores on Posidonia oceanica epiphytes. Aquat Bot 56:93-104

> Barnes DKA, Crook AC (2001) Quantifying behavioural determinants of the coastal European sea-urchin Paracentrotus lividus. Mar Biol 138:1205-1212

> Benedetti-Cecchi L, Bulleri F, Cinelli F (1998) Density dependent foraging of sea urchins in shallow subtidal reefs on the west coast of Italy (western Mediterranean). Mar Ecol Prog Ser 163:203-211

Blevins E, Johnsen S (2004) Spatial vision in the echinoid genus Echinometra. J Exp Biol 207:4249-4253

Boudouresque CF, Verlaque M (2007) Ecology of Paracentrotus lividus. Dev Aquac Fish Sci 37:243-285

Bulleri F, Benedetti-Cecchi L, Cinelli F (1999) Grazing by the sea urchins Arbacia lixula and Paracentrotus lividus Lam. in the Northwest Mediterranean. J Exp Mar Biol Ecol 241:81-95
Bulleri F, Tamburello L, Benedetti-Cecchi L (2009) Loss of consumers alters the effects of resident assemblages on the local spread of an introduced macroalga. Oikos 118: 269-279

- Bulleri F, Cristaudo C, Alestra T, Benedetti-Cecchi L (2011) Crossing gradient of consumer pressure and physical stress on shallow rocky reefs: a test of the stress-gradient hypothesis. J Ecol 99:335-344

> Carpenter RC (1984) Predator and population density control of homing behaviour in the Caribbean echinoid Diadema antillarum. Mar Biol 82:101-108

> Cebrián J, Duarte CM, Marbà N, Enríquez S, Gallegos M, Olesen B (1996) Herbivory on Posidonia oceanica: magnitude and variability in the Spanish Mediterranean. Mar Ecol Prog Ser 130:147-155

Ceccherelli G, Pinna S, Sechi N (2009a) Evaluating the effects of protection on Paracentrotus lividus distribution in two contrasting habitats. Estuar Coast Shelf Sci 81: 59-64

> Ceccherelli G, Pais A, Pinna S, Serra S, Sechi N (2009b) On the movement of Paracentrotus lividus towards Posidonia oceanica seagrass patches. J Shellfish Res 28: 397-473

Chapman MG (2000) Poor design of behavioural experiments gets poor results: examples from intertidal habitats. J Exp Mar Biol Ecol 250:77-95

Collinge SK, Forman RTT (1998) A conceptual model of land conversion processes - predictions and evidence from a microlandscape experiment with grassland insects. Oikos 82:66-84

Crook AC, Long M, Barnes DKA (2000) Quantifying daily migration in the sea urchin Paracentrotus lividus. J Mar Biol Assoc UK 80:177-178

Crowe TP, Underwood AJ (1998) Testing behavioural 'preference' for suitable microhabitat. J Exp Mar Biol Ecol 225:1-11

- Dance C (1987) Patterns of activity of the sea urchin Paracentrotus lividus in the Bay of Port-Cros Var, France, (Mediterranean). Mar Ecol 8:131-142

> Fagan WF, Cantrell RS, Cosner C (1999) How habitat edges change species interactions. Am Nat 153:165-182

Farina S, Tomas F, Prado P, Romero J, Alcoverro T (2009) Seagrass meadow structure alters interactions between the sea urchin Paracentrotus lividus and its predators. Mar Ecol Prog Ser 377:131-137

Fernandez C, Caltagirone A, Johnson M (2001) Demographic structure suggests migration of the sea urchin Paracentrotus lividus in a coastal lagoon. J Mar Biol Assoc UK 81:361-362

Frantzis A, Berthon JF, Maggiore F (1988) Relations trophiques entre les oursins Arbacia lixula et Paracentrotus lividus (Echinoidea Regularia) et le phytobenthos infralittoral superficiel dans la baie de Port-Cros (Var, France). Sci Rep Port-Cros Natl Park 14:81-140

> Guidetti P (2004) Consumers of sea urchins, Paracentrotus lividus and Arbacia lixula, in shallow Mediterranean rocky reefs. Helgol Mar Res 58:110-116

> Hagen NT, Mann KH (1994) Experimental analysis of factors influencing the aggregating behaviour of the sea urchin Strongylocentrotus droebachiensis (Müller). J Exp Mar Biol Ecol 176:107-126

Hagen NT, Andersen Å, Stabell OB (2002) Alarm responses of the green sea urchin, Strongylocentrotus droebachiensis, induced by chemically labelled durophagous predators and simulated acts of predation. Mar Biol 140:365-374 
Hereu B (2005) Movement patterns of the sea urchin Paracentrotus lividus in a marine reserve and unprotected area in the NW Mediterranean. Mar Ecol 26:54-62

Hereu B (2006) Depletion of palatable algae by sea urchins and fishes in a Mediterranean subtidal community. Mar Ecol Prog Ser 313:95-103

Hereu B, Zabala M, Linares C, Sala E (2005) The effects of predator abundance and structural complexity on survival of juvenile sea urchins. Mar Biol 146:293-299

> Jackson AC, Underwood AJ (2007) Application of new techniques for the accurate analysis of choice of prey. J Exp Mar Biol Ecol 341:1-9

> Kadoya T (2009) Assessing functional connectivity using empirical data. Popul Ecol 51:5-15

> Kitching JA, Ebling FJ (1961) The ecology of Lough Ine. XI. The control of algae by Paracentrotus lividus (Echinoidea). J Anim Ecol 30:373-383

Liszka D, Underwood AJ (1990) An experimental design to determine preferences for gastropod shells by hermit crab. J Exp Mar Biol Ecol 137:47-62

Manly B, MacDonald L, Thomas D (1993) Resource selection by animals: statistical design and analysis for field studies. Chapman \& Hall, London

Margules CR, Milkovits GA, Smith GT (1994) Contrasting effects of habitat fragmentation on the scorpion Cercophonius squama and an amphipod. Ecology 75:2033-2042

Nédelec H, Verlaque M (1984) Alimentation de l'oursin Paracentrotus lividus (Lmk) dans un herbier à Posidonia oceanica (L.) Delile en Corse (Mediterranee, France). In: Boudouresque CF, de Grissac AJ, Olivier J (eds) International workshop on Posidonia oceanica beds. GIS Posidonie, Marseille, p 349-364

> Olabarria C, Underwood AJ, Chapman MG (2002) Appropriate experimental design to evaluate preferences for microhabitat: an example of preferences by species of microgastropods. Oecologia 132:159-166

Palacín C, Giribert G, Turon X (1997) Patch recolonization through migration by the echinoid Paracentrotus lividus in communities with high algal cover and low echinoid densities. Cah Biol Mar 38:267-271

> Pinna S, Pais A, Chessa LA, Sechi N, Ceccherelli G (2009) Leaf partitioning of the seagrass Posidonia oceanica between two herbivores: Is Sarpa salpa herbivory underestimated because of Paracentrotus lividus grazing? Estuar Coast Shelf Sci 84:21-27

> Prado P, Alcoverro T, Martínez-Crego B, Vergés A, Pérez M, Romero J (2007) Macrograzers strongly influence patterns of epiphytic assemblages in seagrass meadows. J Exp Mar Biol Ecol 350:130-143

> Prado P, Romero J, Alcoverro T (2009) Welcome mats? The role of seagrass meadow structure in controlling postsettlement survival in a keystone sea-urchin species. Estuar Coast Shelf Sci 85:472-478

Rodriguez SR, Ojeda FP (1998) Behavioural responses of the sea urchin Tetrapygius niger to predators and food. Mar Freshw Behav Physiol 31:21-37

Rosenzweig ML (1981) A theory of habitat selection. Ecology 62:327-335

Russell BD, Gillanders BM, Connell SD (2005) Proximity and size of neighbouring habitat affects invertebrate diver- sity. Mar Ecol Prog Ser 296:31-38

Sala E (1996) The role of fishes in the organization of a Mediterranean subtidal community. PhD thesis, Université d'Aix-Marseille II, Marseille

Scheibling RE, Hamm J (1991) Interactions between sea urchins (Strongylocentrotus droebachiensis) and their predators in field and laboratory experiments. Mar Biol 110:105-116

Shepherd SA (1987) Grazing by the sea urchin Paracentrotus lividus in Posidonia oceanica beds at Banyuls, France. In: Boudouresque CF (ed) Colloque International sur Paracentrotus lividus et les oursins comestibles. GIS Posidonie, Marseille, p 83-96

Singer MC (2000) Reducing ambiguity in describing plantinsect interactions: 'preference', 'acceptability' and 'electivity'. Ecol Lett 3:159-162

> Smith TM, Hindell JS, Jenkins GP, Connolly RM (2008) Edge effects on fish associated with seagrass and sand patches. Mar Ecol Prog Ser 359:203-213

> Taylor PD, Fahrig L, Heinen K, Merriam G (1993) Connectivity is a vital element of landscape structure. Oikos 68: 571-572

> Tischendorf L, Fahrig L (2000) On the usage and measurements of landscape connectivity. Oikos 90:7-19

> Tomas F, Romero J, Turon X (2004) Settlement and recruitment of the sea urchin Paracentrotus lividus in two contrasting habitats in the Mediterranean. Mar Ecol Prog Ser 282:173-184

Tomas F, Turon X, Romero J (2005) Effect of herbivores on a Posidonia oceanica seagrass meadow: importance of epiphytes. Mar Ecol Prog Ser 287:115-125

- Tomas F, Àlvarez-Cascos D, Turon X, Romero J (2006) Differential element assimilation by sea urchins Paracentrotus lividus in seagrass beds: implications for trophic interactions. Mar Ecol Prog Ser 306:125-131

- Underwood AJ, Clarke KR (2005) Solving some statistical problems in analyses of experiments on choices of food and on associations with habitat. J Exp Mar Biol Ecol 318: $227-237$

> Underwood AJ, Chapman MG, Crowe TP (2004) Identifying and understanding ecological preferences for habitat or prey. J Exp Mar Biol Ecol 300:161-187

Verlaque M (1987) Relations entre Paracentrotus lividus (Lamarck) et le phytobenthos de Méditerranée occidentale. In: Boudouresque CF (ed) Colloque international sur Paracentrotus lividus et les oursins comestibles. GIS Posidonie, Marseilles, p 5-36

> Wiens JA, Milne BT (1989) Scaling of 'landscape' in landscape ecology, or, landscape ecology from a beetle's perspective. Landscape Ecol 3:87-96

With KA, Gardner RH, Turner MG (1997) Landscape connectivity and population distributions in heterogeneous environments. Oikos 78:151-169

Yerramilli D, Johnsen S (2010) Spatial vision in the purple sea urchin Strongylocentrotus purpuratus (Echinoidea). J Exp Biol 213:249-255

Zupo V, Fresi E (1984) A study on the food web of the Posidonia oceanica ecosystem: analysis of the gut contents of Echinoderms. International Workshop on Posidonia oceanica beds. GIS Posidonie, Marseille, p 373-379
Editorial responsibility: Antony Underwood, Sydney, Australia
Submitted: March 29, 2011; Accepted: October 20, 2011

Proofs received from author(s): January 9, 2012 